\title{
TTR
}

Traduction, terminologie, rédaction

\section{Territoires, histoires, mémoires : présentation}

\section{Álvaro Echeverri et Georges L. Bastin}

Volume 28, numéro 1-2, 1er semestre-2e semestre 2015

Territoires, histoires, mémoires

Territories, histories, memories

URI : https://id.erudit.org/iderudit/1041647ar

DOI : https://doi.org/10.7202/1041647ar

Aller au sommaire du numéro

Éditeur(s)

Association canadienne de traductologie

ISSN

0835-8443 (imprimé)

1708-2188 (numérique)

Découvrir la revue

Citer ce document

Echeverri, Á. \& Bastin, G. L. (2015). Territoires, histoires, mémoires : présentation. TTR, 28(1-2), 9-12. https://doi.org/10.7202/1041647ar d'utilisation que vous pouvez consulter en ligne.

https://apropos.erudit.org/fr/usagers/politique-dutilisation/ 


\title{
Territoires, histoires, mémoires : présentation
}

\author{
Álvaro Echeverri \\ Georges L. Bastin \\ Université de Montréal
}

«De la traduction nul n'est libre», disait Antoine Berman (1984, p.44). L'ubiquité de la traduction dans le temps et dans l'espace explique la nature inépuisable des problématiques traductologiques. Dans le temps, les traducteurs n'ont pas été avares d'initiatives ni de stratégies en partie remisées dans nos mémoires; dans l'espace, les traducteurs ont franchi d'innombrables frontières et investi nombre de territoires, parfois encore méconnus. Ces mouvements temporels et spatiaux, oubliés voire ignorés, pointent vers les «Blank spaces» répertoriés par Julio César Santoyo en 2004.

En effet, à la problématique néocoloniale, celle des langues nationales et des peuples autochtones, celle des transferts littéraires, celle des échanges commerciaux et technologiques, qui sont loin d'être épuisées, il s'en ajoute constamment d'autres qui ne cessent d'intéresser les traductologues telles la mondialisation et l'écotraduction, la littérature virtuelle, les pratiques émergentes dans les pays en développement. Toutes ces problématiques sont par nature transfrontalières, transnationales et transterritoriales. Traduire, c'est occuper le territoire de l'autre, au propre et au figuré. D'une part, le traducteur s'empare de l'auteur pour le sortir de son environnement et le transporter en d'autres lieux. Par la traduction, un auteur voyage vers d'autres espaces. D'autre part, le texte traduit déplace l'original, il prend sa place, le remplace et le replace. Il peut faire mieux que lui, il peut aussi l'abaisser ou le faire briller.

Cette capacité de la traduction à traverser le temps et à occuper de nouveaux territoires signifie également qu'il devient davantage difficile de cerner ce qui fait ou non partie du territoire traductologique. La traduction transite de la compétence à la performance, de l'intuition à la réflexion, du somatisme au mentalisme, mais sait-on à quoi ces parcours initiatiques ont abouti? 
Les langues autochtones, comme les peuples, leur identité et leurs traditions, perdent du terrain. La récupération, par le truchement de la traduction, des récits oraux des communautés sans tradition écrite contribue à freiner cette perte. La traduction participe à la préservation de la mémoire des mots et des langues, de même qu'à celle des idées, des sensations et des pratiques. La traduction devient ainsi un témoignage des récits fondateurs et formateurs, pour que les peuples restent toujours les principaux responsables de leur propre histoire.

Les études en histoire de la traduction ont joué un rôle primordial dans l'institutionnalisation de la traduction comme domaine de recherche. La prolifération d'anthologies du discours de la traduction, d'encyclopédies et autres Handbooks et Readers le confirme d'ailleurs. D'une histoire centrée principalement sur des problématiques propres à l'Europe de l'Ouest et à son expansion vers l'Amérique du Nord, la traductologie s'est élargie, comme dirait Tymozcko (2007), spatialement et conceptuellement. L'histoire explore aujourd'hui de nouveaux territoires, et cette exploration révèle de nouvelles façons d'appréhender l'objet-traduction. Le métalangage traductologique, créé au fil des décennies, souffre encore d'une indéfinition qui le mine. Les traductologues ont perdu la mémoire ou cherchent à s'en créer une nouvelle. Concepts, approches et modèles s'entrecroisent, s'enrichissent ou se contredisent. Une remise en question s'impose. L'incorporation de méthodologies empruntées à d'autres disciplines, aussi bénéfique soit-elle, doit être compensée par des outils forgés à partir de la matière première traductologique, de l'expérience même des traducteurs. En dépendent la survie et le développement de nos recherches.

Les articles qui composent ce numéro sont issus de communications présentées à l'occasion du congrès annuel de l'Association canadienne de traductologie tenu à St. Catherines en 2014. Madeleine Stratford et Myriam Legault-Beauregard, respectivement professeure et étudiante à l'Université du Québec en Outaouais, présentent une étude sur l'image que les lecteurs mexicains peuvent se faire de la poésie et de la culture québécoises. Pour ce faire, elles ont procédé à une analyse traductologique de l'anthologie Poesía México-Quebec. Il s'agit d'une anthologie réunissant les travaux de poètes mexicains et québécois dont les traductions sembleraient être le fruit d'un travail collaboratif. 
L'analyse des marqueurs de culture québécoise dans l'anthologie leur a permis de conclure que malgré les liens qui unissent les destins de ces deux peuples latins d'Amérique, des efforts devront encore être déployés pour que la culture québécoise soit mieux représentée dans ce type de collaboration. Comme le montrent les auteures dans leur article, certaines décisions concernant la conception graphique et l'édition de cette anthologie soulignent le caractère surtout mexicain de l'ouvrage et la sous-représentation de la culture québécoise.

Aussi intéressée par l'image que peut donner la traduction d'un texte ou d'un peuple, Isis Herrero López s'intéresse pour sa part à l'identité américaine (indianness) dans une perspective multidisciplinaire. Pour ce faire, elle scrute des traductions espagnoles des littératures écrites amérindiennes. Au moyen de l'examen des péritextes de ces traductions (notamment les couvertures), elle met au jour l'image que les traducteurs espagnols donnent des Amérindiens, l'utilisation de celle-ci d'un point de vue linguistique et visuel, et les conséquences de ces représentations culturelles.

À l'instar d'Isis Herrero López qui dénonce la pratique coloniale de promouvoir une image romantique des peuples autochtones, Joshua M. Price, de Binghampton University, se prononce en faveur d'un autre type de décolonisation en analysant un cas concret de traduction intersémiotique. Au centre de sa discussion se trouve le concept de traduction "décoloniale». Il entend par ce concept les pratiques de contre-discours employées par les traducteurs subalternes pour déconstruire les systèmes coloniaux de sens. Son étude prend appui sur une traduction intralinguistique d'un ouvrage américain du $\mathrm{XIX}^{\mathrm{e}}$ siècle et sur la traduction brésilienne d'un poème de John Donne mise en musique par Caetano Veloso.

Continuant ce mouvement vers le sud du continent américain et mettant en relief le rôle décisif joué par les revues culturelles dans l'histoire de la traduction en Amérique latine, la professeure María Constanza Guzmán, de Glendon College, York University, aborde la question identitaire en Amérique latine et dans les Caraibes par le truchement des pratiques de traduction employées par deux revues culturelles du XX $\mathrm{XX}^{\mathrm{e}}$ siècle: Cuadernos de Marcha (Uruguay) et Revista Casa de las Américas (Cuba). Elle se penche notamment sur la sélection des textes à traduire et sur l'adéquation 
de l'image du continent véhiculée par la traduction dans ces revues. L'idée qu'une excellente contextualisation des études afin de produire une image des langues américaine prises séparément est centrale à la discussion de l'auteure.

La capacité de la traduction à franchir les frontières nous amène ensuite vers un autre continent, l'Afrique, et dans un autre type des textes, les textes oraux. Traducteur au Parlement de Yaoundé (Cameroun) et doctorant de l'Université de Liège, Oumarou Mal Mazou examine la traduisibilité de la poésie orale peule, en particulier le mbooku, dans une optique éminemment littéraire. C'est à partir d'un corpus de traductions françaises, anglaises et allemandes, et de ses propres retraductions, qu'il montre la possibilité de faire passer en langues européennes la fonction littéraire des textes oraux originaux. La fonction récupératrice et préservatrice des traditions culturelles et littéraires de la traduction est soulignée dans l'article de Mal Mazou. Aux traductions réalisées par des non-traductologues, Mal Mazou oppose des traductions qui tiennent compte des avancées du discours traductologique afin de mettre en évidence que le regard traductologique peut se concentrer sur les faits de traduction qui échappent aux yeux des anthropologues et des linguistes.

Du Nord au Sud du continent américain et au cœur du continent africain, du texte écrit au texte oral, de la traduction monomodale à la traduction multimodale, les articles de ce numéro témoignent de l'ubiquité de la traduction étudiée sous le prisme de son territoire, de son histoire et de sa mémoire.

\section{Références}

Berman, Antoine (1985). «La traduction et la lettre ou l'auberge du lointain». In Les tours de Babel: essais sur la traduction. Mauvezin (France), Trans-Europ-Repress, p. 34-149.

Santoyo, Julio César (2004). "The Blank Spaces in the History of

Translation». In G. L. Bastin et P. F. Bandia, dir. Charting the Future of Translation History. Ottawa, Les Presses de l'Université d'Ottawa, p. 11-44.

Tymoczko, Maria (2007). Enlarging Translation, Empowering Translators. Manchester, St. Jerome. 